https://helda.helsinki.fi

\title{
Alcohol use and smoking in burn patients at the Helsinki Burn Center
}

\section{Palmu, Raimo}

2018-02

Palmu , R , Partonen , T , Suominen , K, Vuola , J \& Isometsä , E 2018 , ' Alcohol use and

smoking in burn patients at the Helsinki Burn Center ' , Burns , vol. 44 , no. 1 , pp. 158-167 . https://doi.org/10.1016/j

http://hdl.handle.net/10138/298621

https://doi.org/10.1016/j.burns.2017.05.019

publishedVersion

Downloaded from Helda, University of Helsinki institutional repository.

This is an electronic reprint of the original article.

This reprint may differ from the original in pagination and typographic detail.

Please cite the original version. 


\title{
Alcohol use and smoking in burn patients at the Helsinki Burn Center
}

\author{
Raimo Palmu ${ }^{a, b, *}$, Timo Partonen $^{b}$, Kirsi Suominen ${ }^{c}$, Jyrki Vuola $^{d}$, \\ Erkki Isometsä $\ddot{a, b}^{a}$ \\ a Department of Psychiatry, University of Helsinki and Helsinki University Hospital, Helsinki, Finland \\ ${ }^{\mathrm{b}}$ Department of Public Health Solutions, National Institute for Health and Welfare, Helsinki, Finland \\ ${ }^{c}$ City of Helsinki, Social Services and Healthcare, Department of Mental Health and Substance Abuse, Helsinki, Finland \\ ${ }^{\mathrm{d}}$ Helsinki Burn Center, Department of Plastic Surgery, University of Helsinki and Helsinki University Hospital, Helsinki, Finland
}

A R T I C L E I N F O

Article history:

Accepted 25 May 2017

\section{Keywords:}

Alcohol use and smoking at burn

Risk drinking

Heavy smoking

Burn patients

Mental disorders

\begin{abstract}
A B S T R A C T
Objective: We investigated alcohol use and smoking at time of burn and their relationships with severity of burn and presence of mental disorders.

Methods: Consecutive acute burn patients ( $\mathrm{N}=107)$ admitted to the Helsinki Burn Center were assessed with the structured clinical interview for mental disorders (SCID) at baseline and after 6 months. Information regarding being under the influence of alcohol and having smoking-related activity at burn as well as about hazardous drinking (Alcohol Use Disorders Identification Test) and heavy smoking before the burn was recorded.

Results: Around half (52\%) of the acute burn patients were under the influence of alcohol and $19 \%$ had been both drinking and smoking at the time of the burn. Patients under the influence at the time of burn had significantly higher prevalence of lifetime mental disorders compared to those patients who were not under the influence of alcohol $(73.2 \%$ vs. $45.1 \%, p=0.003)$, especially alcohol dependence $(55.4 \%$ vs. $13.7 \%, p<0.001)$ and anxiety disorders $(28.6 \%$ vs. $9.8 \%, \mathrm{p}=0.015)$. Patients who had both alcohol use and smoking at burn had even more often at least one mental disorder ( $95.0 \%$ vs. $51.7 \%, \mathrm{p}<0.001)$, in specific alcohol dependence $(90.0 \%$ vs. $23.0 \%, p<0.001)$, or psychotic disorder $(25.0 \%$ vs. $6.9 \%, p=0.016)$. The main characteristics of the burns themselves did not differ significantly between these groups.

Conclusion: Half of the burn patients were under the influence of alcohol at the time of the burn in this study. In almost all patients where alcohol and smoking contributed to the burn a diagnosable alcohol use disorder was present. Interventions for those with alcohol use disorders and the associated risk behaviors are important for the prevention of burns.
\end{abstract}

(c) 2017 Published by Elsevier Ltd.

\section{Introduction}

Alcohol is one of the major causes of death in developed countries [1,2], and alcohol-related hospital admissions are increasing [1,2]. Previous studies available suggest that among subjects who have been drinking different kinds of traumas are more frequent than among subjects not drinking [3-6]. The relationship between alcohol and trauma [7], specifically

\footnotetext{
* Corresponding author at: Department of Psychiatry, University of Helsinki and Helsinki University Hospital, P.O. Box 590, FI-00029 HUS, Finland. Fax: +358 947163735 .
}

E-mail addresses: raimo.palmu@hus.fi, raimo.palmu@thl.fi (R. Palmu). 
theassociation between alcohol and burns, was widely studied already in the 1980s. However, the methodological heterogeneity in defining of alcohol influence on burn makes it difficult to compare the results of different studies. Howland and Hingson [8] reviewed 32 studies published between 1947 and 1986 of confirmed alcohol-related burns and observed that alcohol was recorded on admission in 1$50 \%$ of cases. In addition, Haum et al. [9] found that $31 \%$ of burn patients had acute alcohol intoxication. In a study measuring blood alcohol level (BAL) at intake, McGill et al. [10] noted the proportion of alcohol-related burns to be $18 \%$. Albright et al. [11] suggested routine alcohol screening on admission because they found that one-third of burn patients were at-risk drinkers and more than one-fourth (29\%) were binge drinkers at least monthly. In a recent British review [1], reported that alcohol-related burns had significantly increased, comprising $20 \%$ of all acute admissions in tertiary burn units. They found that alcohol-related burns are more likely to be caused by flame, to be a strong indicator of underlying alcohol dependence, and to have an adverse effect on burn outcome.

Smoking is also common among burn patients and is another major health problem worldwide with high mortality and morbidity. In a review of Anwar et al. [12], using the years 1981, 1991, and 2001, the trends and associations between smoking, substance abuse, psychiatric history, and burns in England were explored. They found no increase in the proportion of burn patients who smoked, although the number of smokers had increased over this 20-year period. However, the prevalence of smoking, substance abuse, and psychiatric history was consistently high compared with the general population.

Severe burns are life-threatening and devastating traumas $[1,8,9,12]$, to which drinking and smoking may both predispose and complicate. Smoking involves the recurrent lighting of cigarettes, elevating the risk of fires, whereas drinking involves well-known hazards in terms of poor motor coordination and judgment, adding to the risk of burn $[8,9,12]$. However, important clinical epidemiological information related to alcohol and smoking among burn patients remains unknown. Being under the influence of alcohol or smoking at time of the burn may indicate the presence of a substance use disorder. Such findings would have implications for prevention and treatment of burns.

In this study, we compared acute burn patients who had been under the influence of alcohol and/or had smokingrelated activity at the time of the burn with patients who had not. Our aims were to investigate: (1) prevalence rates of alcohol use and smoking-related activity at the time of the burn, (2) the relationships between alcohol use and smoking with burn and treatment, (3) prevalences of mental disorders, particularly alcohol use disorder, among burn patients under the influence of alcohol and/or with smoking-related activity at time of burn, and (4) prevalences of mental disorders, particularly alcohol use disorder, among burn patients with risk drinking or heavy smoking before the burn.

\section{Method}

\subsection{Participants}

Consecutive acute adult burn patients admitted to the Helsinki Burn Center, Finland from 1 May 2006 to 31 October 2007 were eligible for this study. Patients who were Finnish-speaking and at least 18 years old $(n=156)$ were included. However; 19 patients (12.1\%) died and 10 (6.4\%) were transferred to another hospital after immediate care, so could not be interviewed. A further 18 patients (11.5\%) were excluded due to insufficient understanding of Finnish and poor cognitive or sensory abilities. One patient declined to participate, and another withdrew consent after the baseline interview. Therefore, 107 (68.6\% of the total sample) consecutive acute burn patients participated. Information in more detail of this cohort has been published elsewhere previously $[13,14]$. The study protocol was approved by the Ethics Committee of Helsinki University Hospital [13-15]

\subsection{Study procedures and measures}

An experienced psychiatrist (RP) interviewed all consecutive acute burn patients admitted to the Helsinki Burn Center using the Clinician Version of the Structured Clinical Interview for DSM-IV-TR (SCID-CV) for mental disorders [16]. Patients were interviewed on two separate occasions, at baseline (during acute care at hospital) and six months later. Axis I diagnoses were assessed for (a) lifetime (including final month) prior to the burn, (b) one month prior to burn, (c) acute care in hospital, (d) six months follow-up, and (e) the final month of the followup. In total, 104 patients (97.2\%) were interviewed with SCID-II to diagnose personality disorders [17]. Patients also filled out self-report questionnaires to assess different psychological symptoms at baseline and at the end of follow-up. Severity of the burn was evaluated in terms of total body surface area $(\%$ TBSA), and information about sociodemographic factors, earlier diseases, type of treatment, and the burn incident itself was gathered from patient records and by interviews using study forms planned especially for this study. The results of the gathered information have been published in detail previously elsewhere [13-15].

\subsection{Drinking habits before the burn and during follow-up and alcohol influence at burn}

Alcohol Use Disorders Identification Test (AUDIT) $[18,19]$ is a 10-item scale designed to identify individuals with hazardous and harmful drinking during the past 12 months. AUDIT $[18,19]$ was originally planned for primary care and has been widely used among trauma patients. Respondents score between 0 and 4 on each item, and summed scores range from 0 to 40 . Drinking is considered hazardous when the AUDIT sum score for men is $\geq 8$ and for women $\geq 6$. These universal cut-off scores [2,18-20] were used to separate the cohort according to baseline AUDIT sum scores to before the burn "at-risk drinkers" and "not at-risk drinkers" [21,22]. AUDIT was repeated at six 
months after burn. These scores covered the six months between the burn and the second interview.

At baseline, the patient was asked if he or she was "under the influence of alcohol at the time of the burn".

\subsection{Smoking habits, heavy smoking, and smoking-related activity at burn}

During the baseline interview the patients were asked exact questions about their smoking habits over the lifetime and over the final month before the burn as well as at the time of the burn: 1. Have you ever smoked?, 2. Have you smoked regularly during the final month before the burn?, and 3. Did you smoke more than one package of cigarettes a day during the last month prior to burn? If the patient answered "Yes" to question 3, he or she was considered "a heavy smoker". If the patient was smoking or lighting a cigarette at the time of the burn, usually setting the fire ablaze this was defined to be "Smoking-related activity".

\subsection{Statistical analysis}

The data were analyzed with SPSS 16.0 software. Chi-square test, two-sample t-test, and Mann-Whitney U-test (for nonparametric variables such as TBSA) were used as appropriate.

\section{Results}

\subsection{Patients who were under the influence of alcohol at the} time of the burn vs. other burn patients

More than half (52.3\%) of the acute burn patients were under the influence of alcohol at the time of the burn (Table 1). There was no statistically significant difference between women and men (59.4\% vs. $49.3 \%$, NS). Those under the influence of alcohol were more often unemployed (39.3\% vs. $5.9 \%, p=0.001)$ and utilized social assistance during the year prior to the burn (35.7\% vs. $11.8 \%, p=0.01$ ) than those who were not. The groups did not differ in commonness of earlier injuries or psychiatric history, but a history of suicide attempts before burn was more common among those under the influence of alcohol (see Table 1).

Patients who were under the influence of alcohol at the time of the burn had a significantly higher prevalence of mental disorders than those without alcohol influence (Table 1), during lifetime before the burn $(73.2 \%$ vs. $45.1 \%$, $\mathrm{p}=0.003)$, during the final month before the burn $(57.1 \%$ vs. $21.6 \%, p<0.001)$, and during acute care at hospital $(67.9 \%$ vs. $25.5 \%, \mathrm{p}<0.001)$. More specifically, lifetime substance-related disorders before the burn ( $66.1 \%$ vs. $25.5 \%, p<0.001)$, especially alcohol dependence $(55.4 \%$ vs. $13.7 \%, p<0.001)$ were more frequent among patients who were under the influence of alcohol at the time of the burn. Personality disorders were common among acute burn patients (23.4\%) [13] and significantly more common in women than in men (37.5\% vs. $17.3 \%$, $\mathrm{p}=0.024$ ) and in those who were burnt under the influence of alcohol than in those without alcohol influence (37.5\% vs.7.8\%, $\mathrm{p}<0.001)$.
During the six months of follow-up Axis I mental disorders (60.7\% vs. $37.3 \%, p=0.015)$, especially alcohol dependence ( $34.8 \%$ vs. $10.9 \%, p=0.006)$, were also more common among those who had consumed alcohol just before the burn.

The most common type of burn in this cohort of patients was flame (46.7\%). Those under the influence of alcohol had a significantly higher prevalence of flame burns than those without alcohol influence (57.1\% vs. 35.3\%, $p=0.004$ ) (Table 2). Hand burns were more common (51.0 vs. $28.6 \%, p=0.018$ ) among those without alcohol influence at burn. In other burn variables statistical difference between the groups was not explored (see Table 2). Patients who were under the influence of alcohol at the time of the burn did not differ in the frequency of psychiatric consultation or psychiatric care after burn (Supplementary Table 1).

\subsection{The relationship between burns and smoking}

Among the burn patients, daily smoking at sometime during their lifetime before the burn was very common (81.3\%). More than half of the burn patients had been smoking regularly during the month preceding the burn (54.2\%). This was strongly connected to the mental disorders during lifetime before the burn, especially alcohol dependence $(55.2 \%$ vs. $12.2 \%, p<0.001)$ and personality disorders (37.9\% vs. $6.1 \%$, $\mathrm{p}<0.001)$.

The majority of burn patients who were under the influence of alcohol had smoked sometime during their lifetime $(81.3 \%$ vs. $15.9 \%, p=0.005)$, compared to those who were not, and more than half $(54.2 \%$ vs. $45.8 \%, p=0.005)$ had smoked regularly during the month preceding the burn. Almost one-third of these burn patients were heavy smokers during the month preceding the burn.

There was smoking-related activity at the time of the burn among $22.6 \%$ (24 of 107) of patients, and the patients with smoking-related activity differed markedly in their characteristics from those without (Table 3).

\subsection{Both influence of alcohol and smoking-related activity at the time of the burn}

Almost one-fifth (18.7\%) of burn patients and one-third women (31.3\%) had been simultaneously drinking and smoking or lighting a cigarette at the time of the burn (Table 4). Those who had not engaged with these risk activities differed from the group with both alcohol influence and smoking in marital status $(p=0.048)$ and work status $(p<0.001)($ Table 4$)$. They were also significantly less often social assistance recipients $(p<0.001)$. Although these groups of burn patients did not differ in history of previous somatic diseases or serious injuries, the risk behavior group had been significantly more often under the influence of alcohol at an earlier injury $30.0 \%$ vs. $10.3 \%, p=0.005)$. A psychiatric history before the burn was also more frequent in this group, namely psychiatric treatment $(50.0 \%$ vs. $24.1 \%, p=0.013)$, psychiatric hospitalization (30.0\% vs. $6.9 \%, p=0.003)$, and suicidality (30.0\% vs. $9.2 \%$, $\mathrm{p}=0.013)$. The groups did not differ significantly in clinical burn variables, e.g. \%TBSA, but head burns $(65.0 \%$ vs. $32.3 \%$, $\mathrm{p}=0.006$ ) were more common in the risk group (see also the burn variables in Table 2). 
Table 1 - Sociodemographics, psychiatric background, and pre-burn mental disorders of acute burn patients under the influence of alcohol at the time of the burn.

\begin{tabular}{|c|c|c|c|c|c|c|c|}
\hline & \multicolumn{2}{|c|}{ Alcohol influence at burn } & \multicolumn{2}{|c|}{ No alcohol at burn } & \multicolumn{2}{|c|}{ Total } & \multirow[t]{2}{*}{$\mathrm{p}$} \\
\hline & $\mathrm{n}$ & $\%$ & $\mathrm{n}$ & $\%$ & $\mathrm{n}$ & $\%$ & \\
\hline & 56 & 52.3 & 51 & 47.7 & 107 & 100 & \\
\hline Mean age (SD) ${ }^{a}$ & 44.6 & $(14.8)$ & 46.3 & (18.0) & 46.3 & (16.5) & \\
\hline Women $^{\mathrm{b}}$ & 19 & 59.4 & 13 & 40.6 & 32 & 100 & \\
\hline \multicolumn{8}{|l|}{ Marital status } \\
\hline Single & 12 & 23.5 & 12 & 21.4 & 24 & 22.4 & \\
\hline Married or cohabiting & 24 & 42.9 & 30 & 58.8 & 54 & 50.5 & \\
\hline Divorced & 14 & 25.0 & 5 & 9.8 & 19 & 17.8 & \\
\hline Widowed & 6 & 10.7 & 4 & 7.8 & 10 & 9.3 & \\
\hline Work status & & & & & & & $p=0.001$ \\
\hline Employed & 20 & 35.7 & 30 & 58.8 & 50 & 46.7 & \\
\hline Unemployed & 22 & 39.3 & 3 & 5.9 & 25 & 23.4 & \\
\hline Student & 1 & 2.0 & 1 & 1.8 & 2 & 1.9 & \\
\hline Disability pension & 10 & 17.9 & 9 & 17.6 & 19 & 17.8 & \\
\hline Retired & 3 & 5.4 & 8 & 15.7 & 11 & 10.3 & \\
\hline Social assistance recipient ${ }^{c}$ & & & & & & & $p=0.01$ \\
\hline None & 36 & 64.3 & 45 & 88.2 & 81 & 75.7 & \\
\hline Occasionally & 12 & 21.4 & 5 & 9.8 & 17 & 15.9 & \\
\hline As principal income & 8 & 14.3 & 1 & 2.0 & 9 & 8.4 & \\
\hline Earlier serious injury $^{\mathrm{d}}$ & 21 & 38.2 & 16 & 31.4 & 37 & 34.9 & \\
\hline Treatment of psychiatric illness $^{\mathrm{d}}$ & 19 & 33.9 & 12 & 23.5 & 31 & 29.0 & \\
\hline Psychiatric hospitalization $^{\mathrm{d}}$ & 6 & 10.7 & 6 & 11.8 & 12 & 11.2 & \\
\hline History of suicide attempt ${ }^{\mathrm{d}}$ & 11 & 19.6 & 3 & 5.9 & 14 & 13.1 & $p=0.035$ \\
\hline \multicolumn{8}{|l|}{ Mental disorder } \\
\hline At least one mental disorder & 41 & 73.2 & 23 & 45.1 & 64 & 59.8 & $p=0.003$ \\
\hline Any mood disorder & 18 & 32.1 & 11 & 21.6 & 29 & 27.1 & \\
\hline Major depressive disorder & 10 & 17.9 & 6 & 11.8 & 16 & 15.0 & \\
\hline Any anxiety disorder & 16 & 28.6 & 5 & 9.8 & 21 & 19.6 & $p=0.015$ \\
\hline PTSD $^{f}$ & 8 & 14.3 & 0 & 0 & 8 & 7.5 & $p=0.005$ \\
\hline Panic disorder & 2 & 3.6 & 0 & 0 & 2 & 1.9 & \\
\hline Any psychotic disorder & 7 & 12.5 & 4 & 7.8 & 11 & 10.3 & \\
\hline Schizophrenia & 2 & 3.6 & 2 & 3.9 & 4 & 3.7 & \\
\hline Psychotic disorder NOS ${ }^{g}$ & 4 & 7.1 & 1 & 2.0 & 5 & 4.7 & \\
\hline Any alcohol use disorder & 37 & 66.1 & 13 & 25.5 & 50 & 46.7 & $\mathrm{p}<0.001$ \\
\hline Alcohol abuse & 6 & 10.7 & 6 & 11.8 & 12 & 11.2 & \\
\hline Alcohol dependence & 31 & 55.4 & 7 & 13.7 & 38 & 35.5 & $\mathrm{p}<0.001$ \\
\hline Personality disorder & 21 & 37.5 & 4 & 7.8 & 25 & 23.4 & $\mathrm{P}<0.001$ \\
\hline Paranoid & 7 & 12.5 & 1 & 2.0 & 8 & 7.5 & $p=0.038$ \\
\hline Borderline & 14 & 25.0 & 2 & 3.9 & 16 & 15.0 & $p=0.002$ \\
\hline \multicolumn{8}{|l|}{ 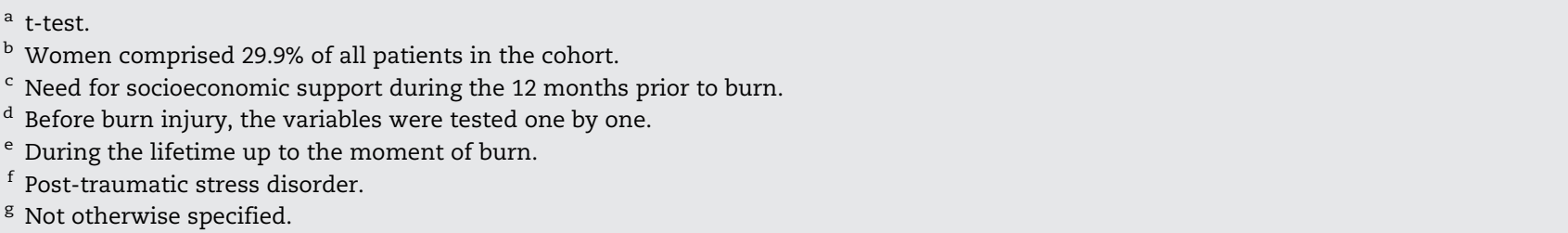 } \\
\hline
\end{tabular}

The prevalence of psychiatric disorders was higher among the risk group before the injury $(95.0 \%$ vs. $51.7 \%, \mathrm{p}<0.001)$, particularly alcohol dependence $(90.0 \%$ vs. $23.0 \%, \mathrm{p}<0.001)$ and psychotic disorders $(25.0 \%$ vs. $6.9 \%, p=0.016)$. During the sixmonth follow-up only the prevalence of alcohol dependence
(55.0\% vs. $14.3 \%, p<0.001)$ differed significantly between the groups. However, there was a marked difference between the groups in the prevalence of personality disorders (55.0\% vs. $16.1 \%$, $\mathrm{p}<0.001$ ). The difference between the genders in this prevalence was significant (women $31.3 \%$ vs. men $13.3 \%$, p=0.03; Table 4). 
Table 2 - Burn-related clinical characteristics of patients under the influence of alcohol at the time of the burn.

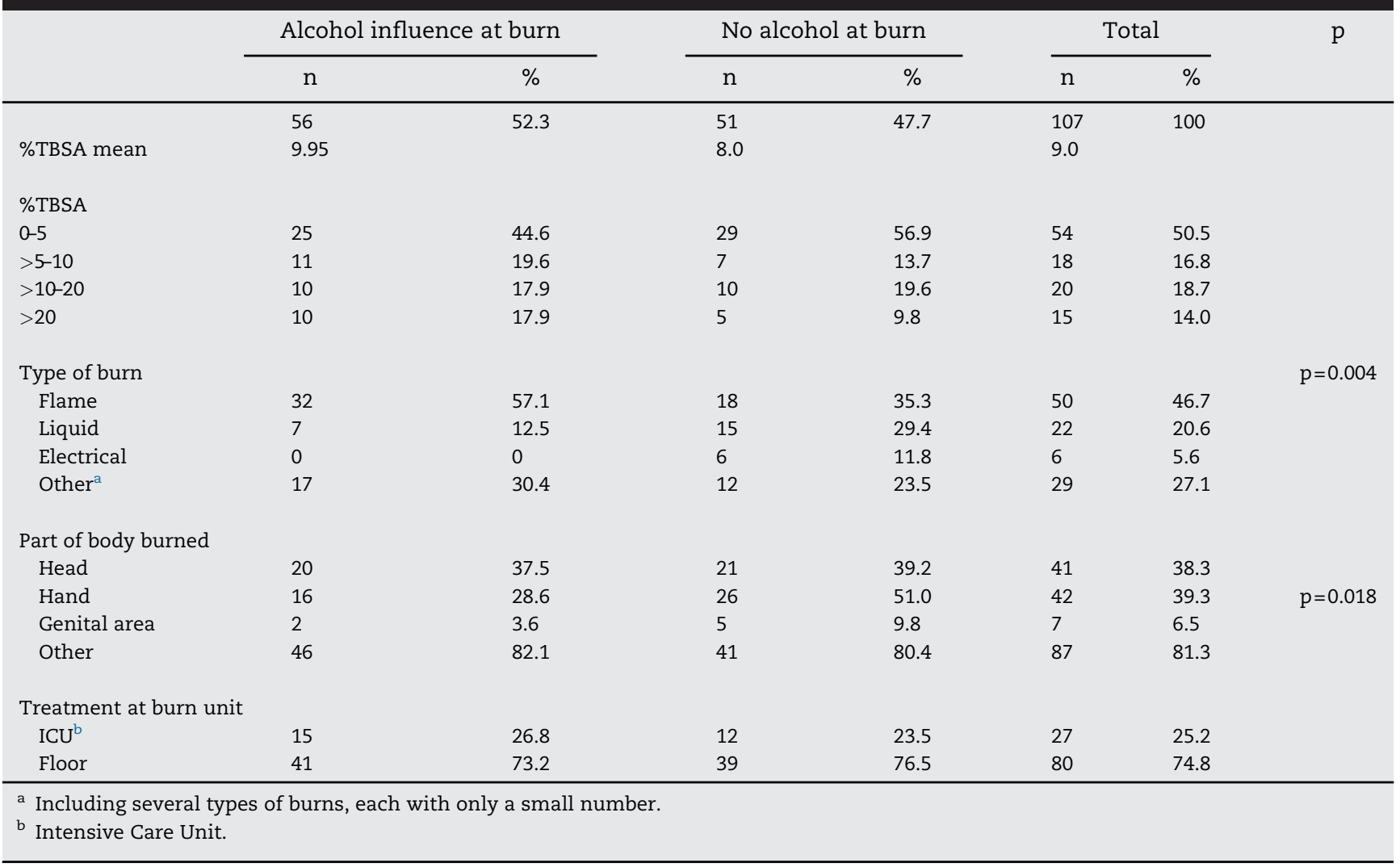

\subsection{At-risk drinkers}

Patients who had hazardous drinking before the burn were significantly older than those who did not drink at an at-risk level (mean age of 49.4 vs. 42.0 years, $p=0.029$; Supplementary Table 2). Patients who were at-risk drinkers were more often living alone $(p=0.011)$, unemployed $(p=0.001)$, and social assistance recipients $(p=0.008)$. Smoking was much more common before the burn $(p<0.001)$ and at the time of the burn $(p<0.001)$ among at-risk drinkers than among the other burn patients.

At-risk drinkers more often had a history of earlier serious injury (46.2\% vs. $22.2 \%, p=0.014)$ and had been under the influence of alcohol, both at an earlier injury $(23.1 \%$ vs. $4.3 \%$, $\mathrm{p}=0.018)$ and at the present burn $(73.1 \%$ vs. $32.6 \%, p<0.001)$. A history of somatic disease before the burn was less common (42.3\% vs. $69.6 \%, p=0.007$ ), but treatment of psychiatric illness ( $42.3 \%$ vs. $13.0 \%, p=0.001)$ and history of suicide attempt $(25.0 \%$ vs. $2.2 \%, p=0.001$ ) before the burn were more common among at-risk drinkers.

At-risk drinkers did not differ from the other burn patients in clinical variables concerning the burn (see also the burn variables in Table 2).

Mental disorders both before the burn (73.2\% vs. $26.2 \%$, $\mathrm{p}<0.001)$ and after the burn $(68.1 \%$ vs. $39.2 \%, p=0.004)$ were more frequent among at-risk drinkers; specifically, major depressive disorder (MDD) before the burn (75.0\% vs. $48.8 \%$, $\mathrm{p}=0.055)$, MDD post-burn (90.9\% vs. $42.5 \%, p=0.003)$, and alcohol dependence before and after burn $(p<0.001)$ were more frequent among at-risk drinkers.

The prevalence of personality disorders overall $(p<0.001)$ and specifically borderline personality disorder $(p=0.003)$ was higher among at-risk drinkers than among other burn patients.

\subsection{Heavy smokers}

Heavy smokers differed from other burn patients in before burn work status $(p=0.036)$; more than one-third of heavy smokers were unemployed (37.5\% vs. $17.3 \%$; Supplementary Table 3). Pre-burn somatic disease was more frequent among those who were not heavy smokers $(69.6 \%$ vs. $42.3 \%, p=0.007)$. Heavy smokers more often had treatment of psychiatric illness (46.9\% vs. $21.3 \%, p=0.008)$, psychiatric hospitalization $(25.0 \%$ vs. $5.3 \%, p=0.003)$, and suicidality ( $31.3 \%$ vs. $5.35 \%, p<0.001)$ pre-burn. They also had smoking-related activity at burn more often than other burn patients ( $41.9 \%$ vs. $14.7 \%, p=0.002)$.

Hand burns were less common among heavy smokers than among other patients ( $25.0 \%$ vs. $45.3 \%, p=0.049)$.

In heavy smokers, lifetime mental disorders overall were more frequent $(90.6 \%$ vs. $46.7 \%, p<0.001)$, especially alcohol dependence $(65.6 \%$ vs. $22.7 \%, p<0.001)$, pre-burn. MDD $(24.4 \%$ vs. $2.3 \%, p=0.003$ ) and alcohol dependence during follow-up ( $41.7 \%$ vs. $16.2 \%, p=0.011$ ) were also more common among heavy smokers.

\section{Discussion}

Of all consecutively admitted acute burn patients to the Helsinki University Hospital, more than half were under the influence of alcohol and almost a quarter had smoking-related activity at burn. The majority of those who had been drinking 
Table 3 - Sociodemographic data, psychiatric background, and pre-burn mental disorders of acute burn patients with smoking-related activity at the time of the burn.

\begin{tabular}{|c|c|c|c|c|c|c|c|}
\hline & \multicolumn{2}{|c|}{ Smoking-related activity } & \multicolumn{2}{|c|}{ No smoking-related activity } & \multicolumn{2}{|c|}{ Total } & \multirow[t]{2}{*}{$\mathrm{p}$} \\
\hline & $\mathrm{n}$ & $\%$ & $\mathrm{n}$ & $\%$ & $\mathrm{n}$ & $\%$ & \\
\hline & 24 & 22.6 & 82 & 77.4 & 107 & 100 & \\
\hline Mean age $(S D)^{a}$ & 44.9 & $(11.1)$ & 45.6 & 17.7 & 45.4 & 16.4 & \\
\hline Women $^{\text {b }}$ & 10 & 31.3 & 22 & 68.8 & 32 & 100 & \\
\hline Marital status & & & & & & & $p=0.022$ \\
\hline Single & 8 & 33.3 & 16 & 19.5 & 24 & 22.6 & \\
\hline Married or cohabiting & 6 & 25.0 & 47 & 57.3 & 53 & 50.0 & \\
\hline Divorced & 8 & 33.3 & 11 & 13.4 & 19 & 17.9 & \\
\hline Widowed & 2 & 8.3 & 8 & 9.8 & 10 & 9.4 & \\
\hline Work status & & & & & & & $\mathrm{p}<0.001$ \\
\hline Employed & 4 & 16.7 & 46 & 56.1 & 50 & 47.2 & \\
\hline Unemployed & 14 & 58.3 & 11 & 13.4 & 25 & 23.6 & \\
\hline Student & 0 & 0 & 2 & 2.4 & 2 & 1.9 & \\
\hline Disability pension & 6 & 25.0 & 12 & 14.6 & 18 & 17.0 & \\
\hline Retired & 0 & 0 & 11 & 13.4 & 11 & 10.4 & \\
\hline Social assistance recipient ${ }^{\mathrm{C}}$ & & & & & & & $\mathrm{p}<0.001$ \\
\hline None & 9 & 37.5 & 71 & 86.6 & 80 & 75.5 & \\
\hline Occasionally & 9 & 37.5 & 8 & 9.8 & 17 & 16.0 & \\
\hline As principal income & 6 & 25.0 & 3 & 3.7 & 9 & 8.5 & \\
\hline Earlier serious injury ${ }^{\mathrm{d}}$ & 8 & 34.8 & 29 & 35.4 & 37 & 35.2 & \\
\hline Treatment of psychiatric illness ${ }^{\mathrm{d}}$ & 14 & 58.3 & 16 & 19.5 & 30 & 28.3 & $\mathrm{p}<0.001$ \\
\hline Psychiatric hospitalization $^{\mathrm{d}}$ & 8 & 33.3 & 4 & 4.9 & 12 & 11.3 & $\mathrm{p}<0.001$ \\
\hline History of suicide attempt ${ }^{\mathrm{d}}$ & 7 & 29.2 & 6 & 7.3 & 13 & 12.3 & $\mathrm{p}=0.004$ \\
\hline \multicolumn{8}{|l|}{ Mental disorder ${ }^{\mathrm{e}}$} \\
\hline At least one mental disorder & 23 & 95.8 & 40 & 48.8 & 63 & 59.4 & $\mathrm{p}<0.001$ \\
\hline Any mood disorder & 10 & 41.7 & 18 & 22.0 & 28 & 26.4 & \\
\hline Major depressive disorder & 6 & 25.0 & 9 & 11.0 & 15 & 14.2 & \\
\hline Any anxiety disorder & 7 & 29.2 & 14 & 17.1 & 21 & 19.8 & \\
\hline PTSD & 0 & 0 & 2 & 2.4 & 2 & 1.9 & \\
\hline Panic disorder & 3 & 12.5 & 5 & 6.1 & 8 & 7.5 & \\
\hline Any psychotic disorder & 6 & 25.0 & 5 & 6.1 & 11 & 10.4 & $p=0.008$ \\
\hline Schizophrenia & 2 & 8.3 & 2 & 2.4 & 4 & 3.8 & \\
\hline Psychotic disorder, NOS & 3 & 12.5 & 2 & 2.4 & 5 & 4.7 & \\
\hline Any alcohol use disorder & 23 & 95.8 & 26 & 31.7 & 49 & 46.2 & $\mathrm{p}<0.001$ \\
\hline Alcohol abuse & 2 & 8.3 & 10 & 12.2 & 12 & 11.3 & \\
\hline Alcohol dependence & 21 & 87.5 & 16 & 19.5 & 37 & 34.9 & $\mathrm{p}<0.001$ \\
\hline Personality disorder & 12 & 48.0 & 13 & 14.8 & 25 & 23.6 & $\mathrm{p}=0.001$ \\
\hline Dependent & 3 & 2.8 & 0 & 0 & 3 & 2.8 & $\mathrm{p}=0.001$ \\
\hline Obsessive-compulsive & 2 & 1.9 & 0 & 0 & 2 & 1.9 & $p=0.008$ \\
\hline Depressive & 3 & 2.8 & 0 & 0 & 3 & 2.8 & $\mathrm{p}=0.001$ \\
\hline Paranoid & 6 & 5.7 & 2 & 1.9 & 8 & 7.5 & $\mathrm{p}<0.001$ \\
\hline Borderline & 7 & 6.6 & 9 & 8.5 & 16 & 15.1 & $\mathrm{p}=0.029$ \\
\hline
\end{tabular}

\footnotetext{
${ }^{a}$ t-test.

b Women comprised $29.9 \%$ of all the patients in cohort.

${ }^{c}$ Need for socioeconomic support during 12 months prior to burn.

d Before burn injury, the variables were tested one by one.

e during lifetime before burn injury, including the moment at burn.
}

just before the burn had a diagnosable alcohol use disorder. Among patients who were burned while lighting a cigarette or smoking, being under the influence of alcohol at burn and having an alcohol use disorder were very common. Moreover, hazardous drinking and heavy smoking pre-burn were very common among acute burn patients.

\subsection{Alcohol and burn patients}

Alcohol use was a major contributing factor in more than half of the acute burn patients in the current sample. In terms of socioeconomic characteristics, they were more often unemployed and needed social assistance during the last pre-burn 
Table 4 - Both smoking-related activity and alcohol influence at the time of the burn.

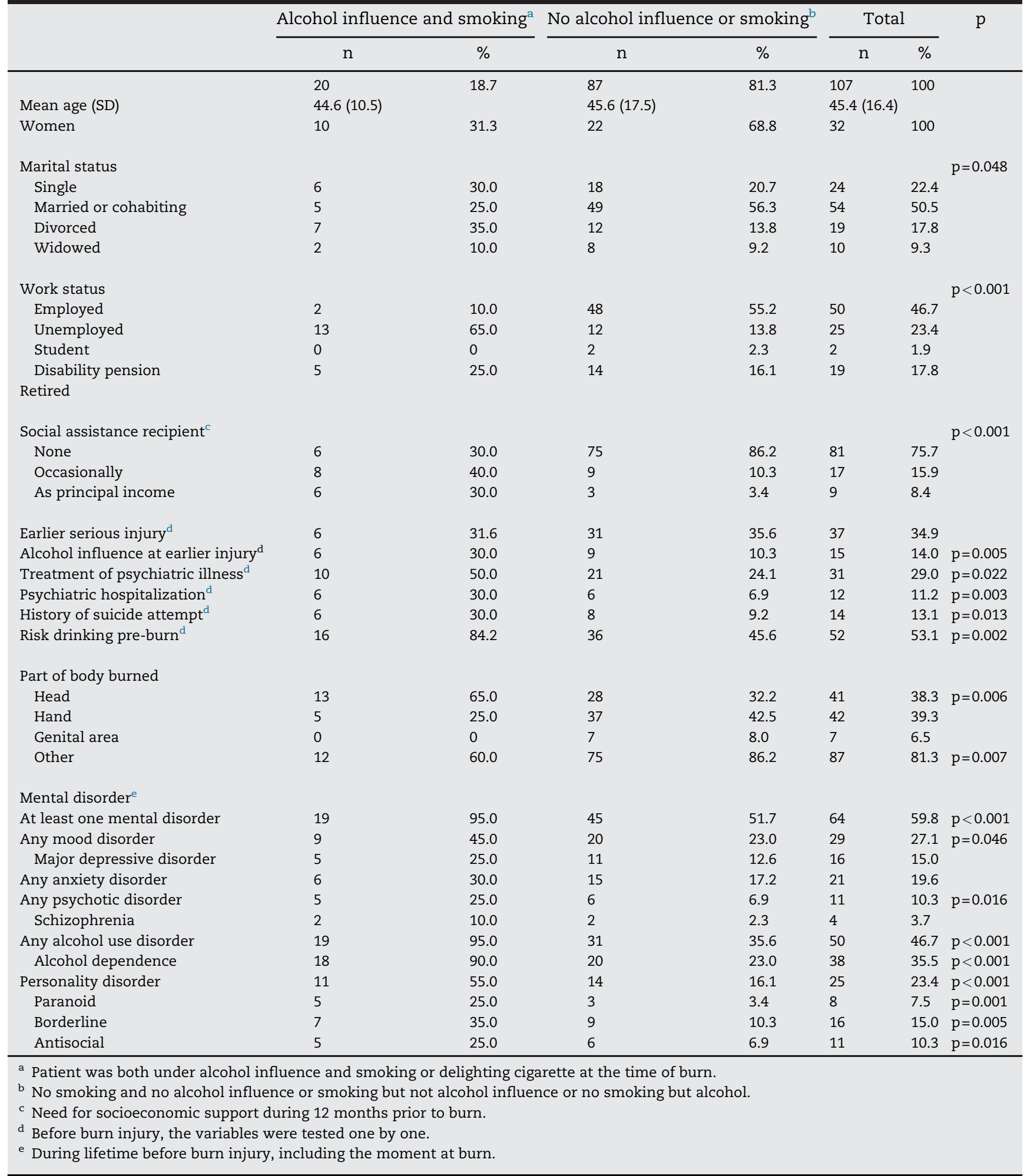

year. Mental disorders were common (60\%) and the prevalence of pre-burn lifetime mental disorders was significantly higher among those who had been under the influence of alcohol at time of the burn than among those who had not been drinking. Pre-burn substance-related disorders, especially alcohol dependence, but also anxiety disorders and personality disorders were more common in those under the influence of alcohol at burn than among those without. Despite the higher prevalence of mental disorders among those burn patients who were under the influence of alcohol, they did not receive psychiatric consultation or care more often than those who had not been drinking just before the burn. We observed and reported the 
naturalistic situation of psychiatric consultation and care among the patients in the cohort $[13,15]$. The reasons for poor recognition of mental disorders in burn treatment as usual or poor possibility for psychiatric consultation among them remain unknown. We did not find similar literature for comparing these results with other studies.

Alcohol-related burns have been defined in variable ways. Holmes et al. [1] recorded an alcohol-related burn when any of the following three criteria were fulfilled: alcohol directly caused the burn or was a significant factor in the burn or the patient was intoxicated at the time of injury [1]. Holmes et al. [1] noted that alcohol-related burns have significantly increased, currently comprising $20 \%$ of all acute admissions in tertiary burn units. In Sweden, Sveen and Oster [21] found that $22 \%$ of the burns were alcohol-related. In our present study, we recorded alcohol influence at burn when the patient admitted to this in the interview. The higher prevalence of alcoholrelated burns in our cohort can be due to differences in catchment areas and our inclusion of all consecutive acute burn patients admitted. Holmes et al. [1] found alcohol-related burns to be a strong indicator of underlying alcohol dependence and to have also an adverse effect on burn outcome.

In addition, we noted that those who were hazardous drinkers before the burn were significantly older, more often living alone, unemployed, and social assistance recipients. These at-risk drinkers had been more often under the influence of alcohol both at an earlier injury and at the present burn. A history of treatment of psychiatric illness and a history of suicide attempts before the burn were more common among at-risk drinkers, but they did not differ significantly from other burn patients in burn variables. Mental disorders both before and after burn, specifically MDD, were more frequent among at- risk drinkers. Alcohol dependence before and after the burn, personality disorders generally, and especially borderline personality disorder were more frequent among at-risk drinkers.

To our knowledge, there are no comparable previous prospective studies of similar kind, including assessment of mental disorders at pre-burn and post-burn interviews. However, Sveen and Oster [21] found that the frequency of alcohol-related burns was not associated with at-risk drinking at 2-to-7-year follow-up, although $25 \%$ of burn patients had an at-risk drinking pattern (AUDIT) at the follow-up. In our earlier study, we found the mean score of AUDIT before the burn in acute burn patients was at a risk level for hazardous drinking and was higher in women than in men [13]. In another study of ours, among acute burn patients paired comparisons of alcohol consumption (AUDIT) at baseline and at the sixmonth follow-up showed a slightly decreasing tendency of alcohol use after burn [14].

\subsection{Smoking and burn patients}

Increased smoking was strongly connected to before burn lifetime mental disorders, especially alcohol dependence and personality disorders. Almost all burn patients who had had smoking-related activity at burn had also been drinking alcohol before burn. The differences in prevalences of lifetime mental disorders between those who had been smoking at burn vs. those not smoking were even stronger than the differences between those under the influence of alcohol vs. those not drinking. Substance-related disorders, especially alcohol dependence, but also anxiety disorders and personality disorders were common among those with smoking-related activity at burn in this study.

Studies reporting smoking at burn are rare. However, in clinical practice we know that lighting a cigarette may put a person in higher risk for burn, especially if a person has long hair or is intoxicated [23]. We did not find studies reporting the complications of burn treatment related to both alcohol and smoking, but Bohn et al. [19] investigated the complications of surgery among orthopedic patients with, for instance, the Drinkcheck questionnaire, a version of AUDIT screening also for tobacco use. The authors concluded that all surgical patients should be screened for alcohol and tobacco use and alcohol withdrawal because they may cause other symptoms, such as behavioral problems, noncompliance, and verbal abuse, complicating post-surgical treatment.

We are unaware of any previous study of burn patients comparing heavy smokers with other burn patients. In our study, heavy smokers differed from other burn patients in before burn work status and more often having treatment of psychiatric illness and/or psychiatric hospitalization and suicidality before the burn. Pre-burn lifetime mental disorders overall were more frequent, especially alcohol dependence, among heavy smokers. MDD and alcohol dependence during follow-up were also more common among heavy smokers. Unexpectedly, however, hand burns and having pre-burn somatic disease were more frequent among the burn patients who were not heavy smokers. Overall, smokers and especially heavy smokers seem to differ from non-smokers in several ways.

\subsection{Study strengths and limitations}

Strengths of this study include that the prospective and longitudinal follow-up was based on a cohort of all consecutive acute hospitalized burn patients admitted over an 18-month period to the Helsinki Burn Center, which at that time treated at least two-thirds of all hospitalized burns and virtually all of the most severe burns in Finland. An experienced psychiatrist interviewed the patients, using a structured diagnostic interview at two time-points, at baseline and at six months, to assess diagnosis for mental disorders. Refusals and withdrawals from the study at baseline were rare. Also during the follow-up drop-outs occurred seldom (14\%). Very few previous studies have used structured clinical interviews in examining mental disorders among burn patients. All patients in the cohort answered the question of alcohol influence and smoking-related activity at burn. AUDIT was filled out at both baseline and six months after burn by 78 of the 86 patients who participated in the follow-up interview. The interview at baseline as well as at six months after burn included questions on smoking in general, regular and heavy smoking, and smoking after burn relative to smoking before burn.

However, the study remains descriptive. We are aware of potential problems related to multiple testing. Further, despite our study sample being larger than in earlier studies that have used structured clinical interviews for assessing mental disorders, the number of cases in specific diagnostic 
subgroups was often small. Although widely used as an overall measure of burn severity, \%TBSA is a gross measure of injury severity. Assessment of alcohol influence at burn could have been more exact, e.g. by measuring blood alcohol level. Finally, generalizability of our findings to other settings remains speculative, as findings are likely to vary due to differences between Finland and other countries in epidemiology of drinking patterns and substance use disorders [24,25]. However, the few previous studies available suggest that among subjects who have been drinking different kinds of traumas are more frequent than among subjects not drinking $[3,5,26]$.

\subsection{Preventive and clinical implications}

Targeted primary prevention of substance-related burn or other injuries must take place in primary healthcare and in psychiatric and substance abuse treatment settings already before a patient enters a burn unit. However, because underlying alcohol dependence mostly seems to exist among burn patients with alcohol influence at burn and those with alcohol influence at burn comprise the majority of acute burn patients, screening of alcohol consumption (e.g. AUDIT at admission) of all burn patients seems necessary. Since preburn mental disorders overall are very common in burn patients and especially alcohol dependence among those burn patients who are under the influence of alcohol at the time of the burn, psychiatric consultation for these patients should take place more often than for the rest of burn patients. Relevant treatment of withdrawal symptoms and other preventive interventions for delirium and optimal treatment of the symptoms of delirium are very important. Miniinterventions for alcohol abuse or other substance use already during acute hospital treatment, and which patients should be referred to a substance use clinic. Withdrawal and cessation of smoking could also be supported and started during the hospital stay [26].

Paying attention to drinking habits during after-care outpatient visits in burn unit may help in preventing readmissions for alcohol-related traumas [6]. Also after discharge from hospital, surgical or rehabilitation interventions should include systematic screening of alcohol consumption (e.g. AUDIT) [26]. Active questioning about drinking and smoking habits is very important in this phase of rehabilitation and can support the return to work [5]. Again active and relevant referral to substance abuse treatment facilities should take place. It can have a preventive impact on future traumas and accidents [3,27].

\section{Conclusions}

About half of hospitalized patients with burn were under the influence of alcohol at the time of the burn. Most of these patients had a diagnosable substance use disorder, mainly an alcohol use disorder, which may complicate treatment of burn although in this study the difference was not significant as in some earlier studies. Furthermore, among one-quarter of patients with smoking-related activity at the time of the burn, concurrent use of alcohol appeared to be common. Moreover, within this subgroup, the prevalence of substance-related disorders was high. Interventions for those with alcohol use disorders and the associated risk behaviors are important for the prevention of burns.

\section{Conflict of interest}

The authors report no conflict of interests.

\section{Appendix A. Supplementary data}

Supplementary data associated with this article can be found, in the online version, at http://dx.doi.org/10.1016/j. burns.2017.05.019.

R E F E R E N C E S

[1] Holmes WJ, Hold P, James MI. The increasing trend in alcoholrelated burns: it's impact on a tertiary burn centre. Burns 2010;36(September (6)):938-43.

[2] World Health Organization, cartographer. Global Status Report on Alcohol and Health 2014 [map]. World Health Organization; 2014.

[3] Williams G, Daly M, Proude EM, Kermode S, Davis M, Barling J, et al. The influence of alcohol and tobacco use in orthopaedic inpatients on complications of surgery. Drug Alcohol Rev 2008;27(1):55-64.

[4] Zatzick D, Donovan DM, Jurkovich G, Gentilello L, Dunn C, Russo J, et al. Disseminating alcohol screening and brief intervention at trauma centers: a policy-relevant cluster randomized effectiveness trial. Addiction 2014;109(May (5)):754-65.

[5] Kelley D, Lynch JB. Burns in alcohol and drug users result in longer treatment times with more complications. J Burn Care Rehabil 1992;13(March-April (2 Pt 1)):218-20.

[6] Rivara FP, Koepsell TD, Jurkovich GJ, Gurney JG, Soderberg R. The effects of alcohol abuse on readmission for trauma. JAMA 1993;270(October (16)):1962-4.

[7] Jurkovich GJ, Rivara FP, Gurney JG, Fligner C, Ries R, Mueller BA, et al. The effect of acute alcohol intoxication and chronic alcohol abuse on outcome from trauma. JAMA 1993; 270(July (1)):51-6.

[8] Howland J, Hingson R. Alcohol as a risk factor for injuries or death due to fires and burns: review of the literature. Public Health Rep 1987;102(September-October (5)):475-83.

[9] Haum A, Perbix W, Hack HJ, Stark GB, Spilker G, Doehn M. Alcohol and drug abuse in burn injuries. Burns 1995; 21(May (3)):194-9.

[10] McGill V, Kowal-Vern A, Fisher SG, Kahn S, Gamelli RL. The impact of substance use on mortality and morbidity from thermal injury. J Trauma 1995;38(June (6)):931-4.

11] Albright JM, Kovacs EJ, Gamelli RL, Schermer CR. Implications of formal alcohol screening in burn patients. J Burn Care Res 2009;30(January-February (1)):62-9.

[12] Anwar MU, Majumder S, Austin O, Phipps A. Smoking, substance abuse, psychiatric history, and burns: trends in adult patients. J Burn Care Rehabil 2005;26(NovemberDecember (6)):493-501.

[13] Palmu R, Suominen K, Vuola J, Isometsä E. Mental disorders among acute burn patients. Burns 2010;36(November (7)): 1072-9.

[14] Palmu R, Suominen K, Vuola J, Isometsä E. Mental disorders after burn injury: a prospective study. Burns 2011;37(June (4)):601-9. 
[15] Palmu R, Suominen K, Vuola J, Isometsä E. Psychiatric consultation and care after acute burn injury: a 6-month naturalistic prospective study. Gen Hosp Psychiatry 2011;33 (January-February (1)):16-22.

[16] First MB, Spitzer RL, Gibbon M, Williams JBW. Structured Clinical Interview for DSM-IV Axis I Disorders, Clinical Version (SCID-CV). Washington, D.C: American Psychiatric Press, Inc.; 1996.

[17] First MB, Spitzer RL, Gibbon M, Williams JBW. Structured Clinical Interview for DSM-IV Personality Disorders, (SCID-II). Washington, D.C: American Psychiatric Press, Inc.; 1997.

[18] Saunders JB, Aasland OG, Babor TF, de la Fuente JR, Grant M. Development of the alcohol use disorders identification test (AUDIT): WHO collaborative project on early detection of persons with harmful alcohol consumption-II. Addiction 1993;88:791-804.

[19] Bohn MJ, Babor TF, Kranzler HR. The Alcohol Use Disorders Identification Test (AUDIT): validation of a screening instrument for use in medical settings. J Stud Alcohol 1995;56 (July):423-32.

[20] Halme JT, Seppa K, Alho H, Pirkola S, Poikolainen K, Lonnqvist $\mathrm{J}$, et al. Hazardous drinking: prevalence and associations in the Finnish general population. Alcohol Clin Exp Res 2008; 32(September (9)):

1615-22.
[21] Sveen J, Oster C. Alcohol consumption after severe burn: a prospective study. Psychosomatics 2015;56(July-August (4)):390-6.

[22] Imani G, Barrios C, Anderson CL, Hosseini Farahabadi M, Banimahd F, Chakravarthy B, et al. Computerized alcohol screening identified more at-risk drinkers in a level 2 than a level 1 trauma center. BMC Public Health 201717(January (1)) 32,016-3989-6.

[23] Koljonen V. Long hair, smoking, and deep facial burns. J Burn Care Res 2008;29(March-April (2)): 395-7.

[24] Makela P, Mustonen H, Lintonen T. Connection between drinking context choices and self-reported alcohol-related social harm: results from the Finnish drinking habit survey 2008. Drug Alcohol Rev 2016;35(March (2)):187-95.

[25] Bonomo YA, Bowes G, Coffey C, Carlin JB, Patton GC. Teenage drinking and the onset of alcohol dependence: a cohort study over seven years. Addiction 2004;99(December (12)):1520-8.

[26] Zatzick D, Donovan DM, Jurkovich G, Gentilello L, Dunn C, Russo J, et al. Disseminating alcohol screening and brief intervention at trauma centers: a policy-relevant cluster randomized effectiveness trial. Addiction 2014;109(May (5)):754-65.

[27] Dinh-Zarr T, Goss C, Heitman E, Roberts I, DiGuiseppi C. Interventions for preventing injuries in problem drinkers. Cochrane Database Syst Rev 2004;(3):CD001857. 